\title{
Social connectivity and adaptive capacity strategies in large-scale fisheries
} Iratxe Rubio $^{1,2}$. Jacob Hileman $^{3}$ and Elena Ojea $^{2}$

\begin{abstract}
Large-scale fisheries are important social-ecological systems that are increasingly being threatened by global climate change. Adaptive capacity is key for moving fisheries onto climate resilient pathways, however, implementing policies to improve adaptive capacity is challenging given the many diverse stakeholders involved in fisheries. Previous research suggests social networks are integral to adaptive capacity because social connectivity can enable, or constrain, knowledge and information sharing. We examine the network of communication among stakeholders in the Basque tropical tuna freezer purse seine fishery in the eastern Atlantic Ocean. We use cluster analysis, descriptive statistics, and exponential random graph models to assess whether different types of actors, occupying different network positions, value similar adaptive capacity strategies. The results indicate that many actor types are frequently connected within the fishery. Preferences for adaptive capacity strategies vary within and across actor types, and the preferences of highly central actors are generally more homogeneous and narrowly focused. All actors agree on the importance of the social organization domain from adaptive capacity, while fishing industry representatives tend to have the most holistic perspective on adaptive capacity overall. We discuss the implications of these findings as they relate to policies for supporting adaptive capacity and climate resilient fisheries.
\end{abstract}

Key Words: adaptative capacity; global climate change; governance; social network analysis; tropical tunas

\section{INTRODUCTION}

Large-scale fisheries are increasingly being threatened by a range of anthropogenic pressures, including pollution, overfishing, habitat degradation, and climate change (Halpern et al. 2019). Climate change, in particular, has the potential to transform marine ecosystems at a global scale, and is already impacting the demography, distribution, and phenology of marine species (García Molinos et al. 2016, Poloczanska et al. 2016, Free et al. 2019). It is widely recognized that these impacts will result in fisheries production being altered and catch potential redistributed regionally, and that this has significant socioeconomic implications for those with fisheries-dependent livelihoods (Lam et al. 2016, Free et al. 2019). That these distribution shifts are transboundary, that they occur across human-defined political and administrative boundaries, further suggests conflict over new shared fisheries may arise (e.g., Spijkers and Boonstra 2017), which poses an additional burden to the sustainable governance of fisheries (Pinsky et al. 2018). Indeed, many of the expected impacts of climate change are already being felt in both the ecological and social dimensions of fisheries (IPCC 2019).

Fisheries are complex social-ecological systems (SES) characterized by interdependencies among numerous ecological, social, economic, and institutional components across multiple scales (Berkes 2011, Partelow 2018). Human behavioral responses, in this case fishing practices, react to ecological change and multiple social and economic constraints, and also drive ecological change (Perry et al. 2011). An emerging view of fisheries management emphasizes the need to integrate the holistic perspective of SES approaches to improve solutions to current fishing resource dilemmas. These include sustainable management of fisheries and promoting resilient fisheries (Partelow and Boda 2015, Cenek and Franklin 2017, Marshall et al. 2018, Holsman et al. 2019), which are especially important in the context of rapid climatic change (Ogier et al. 2020). However, accounting for such interconnections is a difficult task in empirical research.

The use of network analysis as a means of understanding interdependencies in complex SES has emerged as its own subfield of governance research over the past two decades (Janssen et al. 2006, Bodin and Tengö 2012, Bodin 2017, Bodin et al. 2019, Barnes et al. 2020), including a substantial number of empirical studies of fisheries (e.g., Fuller et al. 2017, Alexander et al. 2018, Yletyinen et al. 2018). Social networks have played a crucial role in cases where diverse public and private actors have come together to effectively address resource governance challenges (Olsson et al. 2008, Cinner et al. 2012, Lleonart et al. 2014, Rivera et al. 2014, Pita et al. 2016). Moreover, social networks can help enable collective action and knowledge sharing around adaptive capacity (Adger 2003, Pelling et al. 2008), which is key for the effective governance and long-term sustainability of fisheries in the face of global climate change (Lindegren and Brander 2018).

Adaptive capacity is defined as "the ability of systems, institutions, humans and other organisms to adjust to potential damage, to take advantage of opportunities, or to respond to consequences" (IPCC 2018:542). We draw on research from Cinner et al. (2018) to frame adaptive capacity in the social dimension of fisheries governance, which is composed of five domains: social organization, assets, flexibility, learning, and agency. This framework is more comprehensive than conventional approaches, where investments to improve individuals' capacities to adapt to changes tend to focus on a narrow view of adaptive capacity, for example, building financial assets (Barnes et al. 2020). Thus, understanding which domains are most valued by actors in a fishery can aid the development of specific adaptation strategies and policies for supporting sustainable and resilient fisheries.

\footnotetext{
${ }^{1}$ Basque Centre for Climate Change BC3, ${ }^{2}$ Future Oceans Lab, CIM-Universidade de Vigo, Spain, ${ }^{3}$ Stockholm Resilience Centre, Stockholm University, Stockholm, Sweden
} 
In this paper, we examine the social network of communication among stakeholders in a large-scale international fishery: the Basque tropical tuna fishery. The objective is to investigate whether social connectivity is linked to actors' preferences for adaptive capacity strategies, with the goal of maintaining the fishery in the future (i.e., to be sustainable) and in the face of global climate change (i.e., to be resilient). Adaptation actions are manifestations of adaptive capacity (Smit and Wandel 2006), and our aim here is to identify in which adaptive capacity domains actions are likely to have the greatest influence, and which actors might facilitate them. To this end, we use descriptive statistics and exponential random graph models (ERGMs) to explore two broad research questions: (1) Which adaptive capacity strategies are valued by which actors? (2) Do the adaptive capacity strategies valued by actors vary according to their positions in the network?

To address these research questions, we first frame the Basque tropical tuna fishery as a complex SES and identify its core components. Examining the composition of the SES is necessary to correctly identify all relevant stakeholders in the governance network. Next, we describe the in-depth, high-level expert interviews we used to validate the characterization of the fishery as a SES, measure social connectivity among actors, and elicit actors' preferences for different adaptive capacity strategies. We employ network analysis to study social connectivity, i.e., communication, in the fishery. Our empirical findings demonstrate the link between adaptive capacity preferences and the structure of social connectivity, and suggest several targeted adaptation strategies. Moreover, the approach helps identify central actors with particular views on adaptive capacity. We then discuss the findings as they relate to adaptive capacity for sustainable and climate resilient fisheries, and highlight policy implications and considerations for future research.

\section{THEORY}

\section{Large-scale fisheries as complex social-ecological systems}

Social-ecological systems theory describes how human societies and the environment are interconnected and co-evolve across spatial and temporal scales, forming complex adaptive systems (Preiser et al. 2018). In this paper, we draw on the work of Ostrom and McGinnis (Ostrom 2009, McGinnis and Ostrom 2014) to establish the theoretical framing for studying the Basque tropical tuna SES. McGinnis and Ostrom (2014) provide a framework for studying SES that has been broadly used in resource governance settings, including water, forests, and fisheries, among others, as a tool to diagnose sustainability (Partelow 2018). In the context of fisheries, the SES framework has mostly been applied to the study of small-scale fisheries (e.g., Leslie et al. 2015, London et al. 2017). At present, relatively few empirical studies have applied the framework to large-scale fisheries (see Partelow 2018). Given the economic importance of large-scale fisheries around the world, coupled with the impacts global climate change is already having on fisheries, expanding the scope of empirical SES studies to include large-scale fisheries is a key contribution to the literature.

Epstein et al. (2014) investigated how the SES framework could be scaled up from small-scale to large-scale fisheries, using the Atlantic Bluefin tuna fishery as a case study and focusing on the International Commission for the Conservation of Atlantic
Tunas (ICCAT) governance regime. They highlighted the omission of resource users from the ICCAT as a major issue, and discussed how it derived from both a lack of information and the international nature of the governance system. According to the authors, rule making occurred at the international level with little direct input from resource users, which disregards the principle of user participation and collective-choice rules that SES theory has identified as necessary for effective and sustainable governance (Ostrom 1990, Cox et al. 2010). In view of these findings, to address the resource users limitation we define a largescale fishery as an SES using a bottom-up approach; we include local-level resource users from an international fishery and their interactions with actors at higher levels, i.e., national, regional, and international organizations. The resource users here are at the base of the SES definition in the context of the ICCAT governance regime. As a note on terminology, we use "actors" and "organizations" interchangeably.

\section{Framing adaptive capacity in large-scale fisheries}

We use the coastal communities adaptive capacity framework developed by Cinner et al. (2018), as well as recommendations from other recent studies (Whitney et al. 2017, Freduah et al. 2018), in our formulation of adaptive capacity in large-scale fisheries. As previously mentioned, this framework divides adaptive capacity for climate change into five domains: assets, flexibility, social organization, learning, and agency. Assets include all the private and public resources actors can access in times of need, e.g., savings, technology, and health care. Flexibility refers to the institutional or individual capacity for switching between adaptation strategies to deal with change, e.g., diversifying income sources. Social organization describes how actors are interconnected, and whether such connections enable or inhibit cooperation, collective action, and knowledge sharing, e.g., building connections between the fishing industry and scientific organizations to create access to information that facilitates adaptation. Learning refers to actors' capacities to generate and process information, and assess potential response strategies, e.g., being informed about the status of fish stocks. Agency is the ability of actors to choose from multiple strategies when responding to environmental change, and to mobilize the other adaptive capacity domains.

These five broad domains form the conceptual foundation of the dimensions of adaptive capacity. Thus, in order to operationalize the framework and apply it to our case study of the Basque tropical tuna fishery, we define a set of specific adaptive capacity strategies for each domain of adaptive capacity, drawing on examples from the literature (Whitney et al. 2017, Freduah et al. 2018; Table 1).

\section{Social connectivity and adaptive capacity preferences}

A social network is an interconnected system comprising a set of actors (nodes) such as organizations, individuals, institutions, or communities, and the formal and/or informal relationships (links) that exist among them (Scott and Carrington 2014). In studies of social networks, the focus is on how the structure of social relations among actors may influence the behavior of individuals, groups of actors, or the system as a whole (Bodin and Crona 2009, Scott and Carrington 2014). In the context of natural resource governance, patterns of collaboration among actors can shed light on participation, group learning, resource distribution, and other 
social processes (Lubell 2013, Mancilla-García and Bodin 2019), as well as biophysical and socio-political outcomes (de Lange et al. 2019). Studies of resource governance networks often specifically seek to explain why certain actors do, or do not, adopt certain management practices or policy beliefs, accounting for both endogenous, i.e., network structure, and exogenous variables, i.e., attributes of the actors or their relationships.

Table 1. Adaptive capacity domains by Cinner et al. (2018) and the specific adaptive capacity strategies examined in our study.

\begin{tabular}{ll}
\hline \hline $\begin{array}{l}\text { Domains of } \\
\text { adaptive capacity } \\
\text { from Cinner et al. } \\
(2018)\end{array}$ & Adaptive capacity strategies used in this study \\
\hline Assets & $\begin{array}{l}\text { (a) Specific infrastructure (e.g., ports, vessels) } \\
\text { (b) Credit or savings } \\
\text { (c) Public funding }\end{array}$ \\
Organization & $\begin{array}{l}\text { (d) Well connected with other actors } \\
\text { (e) Participation in international/national/local } \\
\text { forums } \\
\text { (f) Quality of governance and leadership } \\
\text { (g) Income diversity } \\
\text { (h) Level of dependence on natural resources } \\
\text { (i) Knowing that the environment is continuously } \\
\text { changing including the species and ecosystems } \\
\text { (j) Intergenerational learning capacity } \\
\text { (k) Resource status assessment and feedback } \\
\text { mechanisms } \\
\text { (l) Ability to react to changes (e.g., distribution, } \\
\text { abundance, climatic risks) }\end{array}$ \\
\hline${ }^{\dagger}$ Based on Whitney et al. (2017), Cinner et al. (2018), and Freduah et al. \\
(2018).
\end{tabular}

The specific focus of this paper is on the relationship between communication (links) among organizational stakeholders (nodes) in a large-scale fishery, and stakeholders' preferences for adaptive capacity strategies in the context of climate change. To the extent that social connectivity is associated with the adaptive capacity domains that stakeholders prefer, it is possible to develop targeted strategies for supporting adaptive capacity in fisheries that are informed by social connectivity. Highly central actors are well positioned to share information widely throughout their networks (Gibbs 2008, Bodin and Crona 2009, de Lange et al. 2019). If these actors have a more comprehensive view of adaptive capacity domains, that they are able to spread this information readily through their network may be an advantageous feature of the governance system. However, if central actors have narrower views on adaptive capacity domains, then this may limit other actors' views and potentially reduce adaptive capacity in the fishery. Also, it is not uncommon that similar actors share similar views, a phenomenon known as "homophily" in social networks (McPherson et al. 2001), and therefore communication across groups may be important for supporting a holistic, industry-wide approach to adaptive capacity.

\section{CASE STUDY}

\section{Background}

Tuna species are among the most valuable marine species in the world, accounting for $20 \%$ of the value of all marine capture fisheries, and over $8 \%$ of all globally traded seafood (FAO 2018). Tropical tunas, i.e., Skipjack tuna (Katsuwonus pelamis),
Yellowfin tuna (Thunnus albacares), and Bigeye tuna (Thunnus obesus), represent $75 \%$ of tuna and tuna-like global catches (FAO 2018). These marine resources are targeted by large-scale purse seiners among other gears. Tropical tuna freezer purse seiners owned by Spanish companies fish around $10 \%$ of the global catch of tropical tunas (Ugalde and Samano 2019), and the majority of these vessels are Basque, i.e., controlled by Basque capital (Ugalde 2014). In total, 66 Spanish and Basque tuna freezer vessels (including convenience flags) operate in the Pacific, Atlantic, and Indian Oceans (Ugalde and Samano 2019). Among them, 18 Basque tuna freezer purse seiners operated in the eastern Atlantic Ocean in 2019. Our case study focuses specifically on this fishery and builds on previous research of climate change distribution impacts. At the ecological level, tuna habitat distribution limits are already shifting poleward as a response to climate change (Erauskin-Extramiana et al. 2019). At the fishery level, purse seiners have also shifted in the last 30 years as a combination of climatic, technological, and management forces (Rubio et al. 2020).

Regarding the governance regime, the ICCAT is the Regional Fisheries Management Organization (RFMO) responsible for the management and conservation of tuna and tuna-like species in the Atlantic Ocean. Decisions are taken by contracting parties (each country gets one vote, except for countries within the European Union [EU] who are represented under a single vote of the EU). In this context, since 2005 the Bigeye tuna stock has a total allowable catch (TAC) allocated to countries, although it is overfished and overfishing is actively occurring (ICCAT "red status"). The eastern Yellowfin tuna stock has had a general TAC since 2012, which has not been allocated to fishing countries, and yet is considered to be doing well (ICCAT "green status"). Finally, the eastern Skipjack tuna stock has no TAC and is also doing relatively well (ICCAT, "green status"; ICCAT 2016, 2019).

\section{SES characterization of the case study}

We characterize the Basque tropical tuna fishery as a complex SES comprising the four core sub-systems described by Ostrom (2009): resource system, resource units, governance system, and users (corresponding to the broader "actors" subsystem as defined in McGinnis and Ostrom 2014). All of the characteristics of the social, economic, and political settings, related ecosystems, and their interactions complement these four sub-systems (McGinnis and Ostrom 2014). Users represent the industrial extractive activity of tropical tunas by Basque freezer purse seine vessels in the eastern Atlantic Ocean. We conceptually illustrate the fishery as a SES (Fig. 1), and highlight the impacts of climate change on the SES as drivers, and adaptive capacity and sustainability as outcomes. Many different organizations are present in the Basque tropical tuna SES, and we distinguish the following four groups of actors: the fishing industry, government bodies and the RFMO, research bodies, and non-governmental organizations (NGOs) and others, e.g., non-profit organizations.

The fishing industry includes the primary users engaged in the extraction of tropical tunas in the Atlantic Ocean, which are four Basque companies represented in two fisheries associations. Government bodies actively participate in the decision-making process about allocation of fishing possibilities and resource management at the international level as part of the RFMO, i.e., the ICCAT. We identify four government groups: (A) the regional 
Fig. 1. Conceptual representation of the Basque tropical tuna fishery as a complex socialecological system (SES) under climate change. Adding up numbers within boxes, 23 organizations are accounted for, which correspond to the network nodes in Figure 4 ( 20 of them are specific organizations from which 13 were interviewed). The original figure used during interviews is Figure A1.1. RFMO = Regional Fisheries Management Organization.

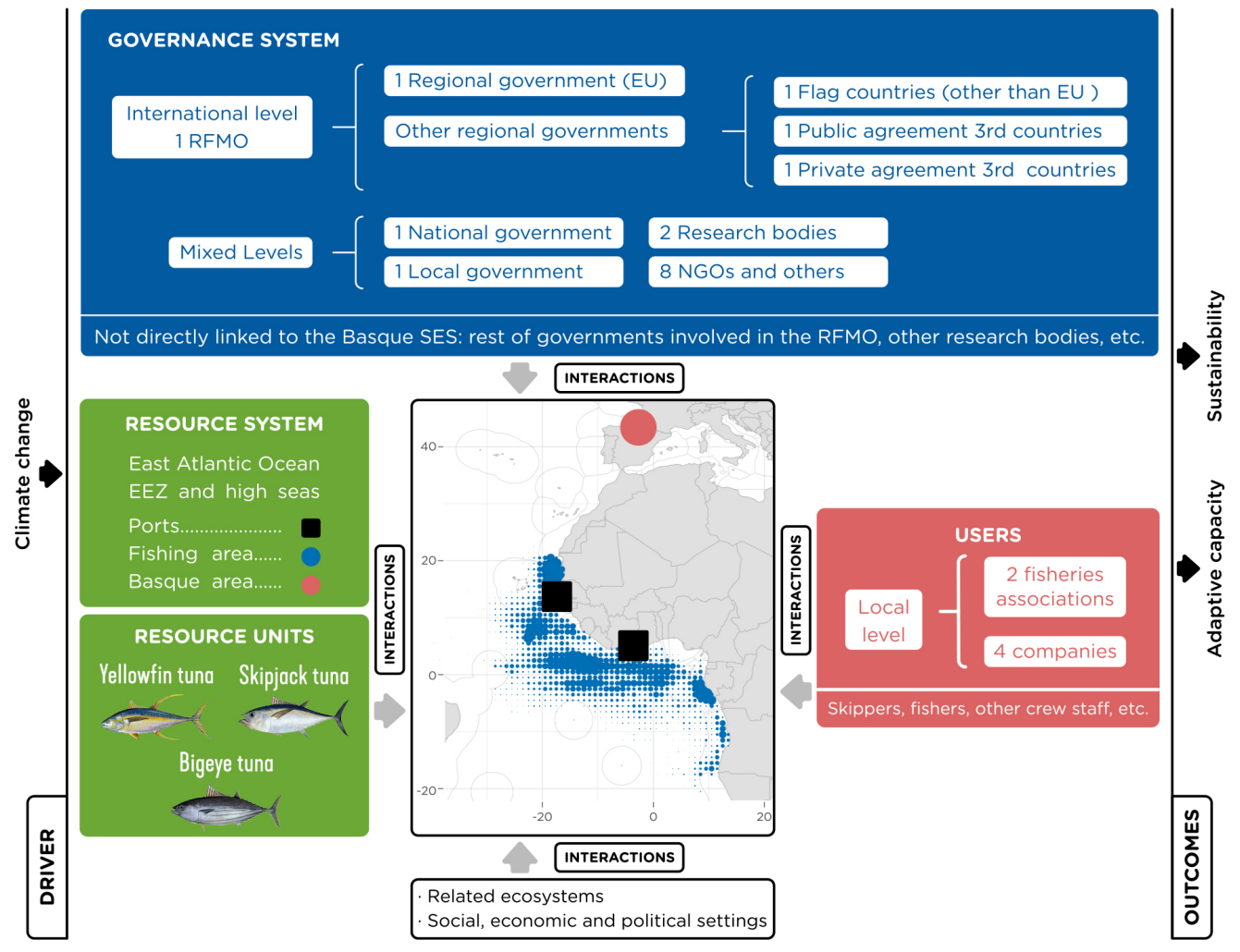

government of the European Union; (B) other regional governments that are flag countries of Basque vessels (non-EU); (C) other regional governments with public or private agreements for the fishery; and (D) national and local governments. Groups $\mathrm{B}$ and $\mathrm{C}$ are non-exclusive; one regional government can be part of both groups depending on its relationship with the resource users. Although the national government regulates the fishery at the country level, the local government plays a more specific role in the fishery, e.g., processing requests for constructing new vessels. Research bodies inform decision making in the fishery with the best available science and develop research projects with different actors (two research bodies are related to the Basque tuna SES). NGOs and other organizations typically focus on conservation of resources and the long-term sustainability of fisheries. In total, there are eight NGOs and other organizations that participate in the governance system of the Basque tropical tuna fishery. Last, it is important to note here the "high-level" nature of this study. We are not looking at every individual actor, e.g., vessels, crewmembers, etc., but rather at organizations and institutions in order to capture coordination at a higher level of decision making.

\section{DATA AND METHODS}

The Basque tropical tuna fishery represents a large-scale fishery with important economic value and pressing sustainability challenges, and provides a compelling context for empirically addressing our research questions on social connectivity and preferences for adaptive capacity strategies. We begin by using the SES framework to describe the fishery and identify the actors involved, who we then invited for in-depth interviews to collect information on their adaptive capacity preferences and communications with other stakeholders. We used cluster analysis to group actors with similar preferences, and used social network analysis to investigate the structure of communication among actors and how they relate to adaptive capacity preferences. All analyses were performed using the R Environment for Statistical Computing (R Core Team 2018), and the scripts with their workflow are available here: https://github.com/irrubio/ tropituna SNA AdaptCapacity.

\section{Stakeholder interviews}

We designed a questionnaire (available in Appendix 1) for carrying out in-depth, semi-structured interviews with the relevant stakeholders in the Basque tropical tuna SES. One high-level representative, such as the director, from each organization was invited to participate (Table 2). Organizational stakeholders were identified through the authors' professional networks and knowledge of the empirical setting, and participants were also given the chance to nominate other stakeholders during the interviews, drawing on their own experience and knowledge 
(Bryman 2016). After disclosing the general objective of the study to invited participants, without providing information that could alter their responses, and informing them about confidentiality and their rights during the interview process, they were asked for their voluntary participation in the interviews. We were able to conduct thirteen in-depth interviews, corresponding to $65 \%$ of the twenty specific organizations identified to be directly related to the Basque fishery (nominated in Figure 1). We did not interview national governments at the international scale because of lack of access to representatives of these governments, who correspond to "Other regional governments" in Figure 1.

Table 2. Actor type, position, number $(\mathrm{n}=13)$, and Ostrom's social-ecological systems (SES) framework category corresponding to stakeholders interviewed. RFMO $=$ Regional Fisheries Management Organization.

\begin{tabular}{lll}
\hline \hline Actor type & $\begin{array}{l}\text { Position of person(s) } \\
\text { interviewed (number) }\end{array}$ & $\begin{array}{l}\text { Ostrom's SES framework } \\
\text { category }\end{array}$ \\
\hline $\begin{array}{l}\text { Government or } \\
\text { RFMO } \\
\text { Research }\end{array}$ & Division directors (2) & Governance system actors \\
NGO, others & $\begin{array}{l}\text { Coordinator of research area (1) } \\
\text { Principal researcher (1) } \\
\text { Division vice president (1) }\end{array}$ & \\
Fishing industry & $\begin{array}{l}\text { Fisheries responsible (2) } \\
\text { Managing directors (4) }\end{array}$ & Users (or actors in \\
& $\begin{array}{l}\text { Deputy director (1) } \\
\text { Area director (1) }\end{array}$ & $\begin{array}{l}\text { McGinnis and Ostrom } \\
\text { 2014) }\end{array}$ \\
\hline
\end{tabular}

The interviews were carried out over January to April 2019, including 11 in-person interviews and two video calls. Interviews lasted one hour and 20 minutes, on average. All interviewees were male and had been working in the fishing sector for an average of 18 years. Forty-six percent of interviewees were between 35 and 44 years old, $31 \%$ between 45 and 54 , and 23\% between 55 and 64. Despite having targeted representatives of top organizations, most of the respondents considered their organization to have little influence in decision-making processes. As much as $54 \%$ considered their organization to have very little influence, $38 \%$ moderate influence, and only $8 \%$ a lot of influence.

During the interview, stakeholders were asked about three main topics: (1) their understanding of the Basque tropical tuna SES; (2) communication exchanges between their organization and other organizations; and (3) the adaptation actions and adaptive capacity strategies needed to maintain the fishing activity in the long term (see questions in Appendix 1).

For the stakeholders' understanding of the SES (1), interviewees were asked about the components of the case study using the diagram of the conceptual model of the Basque tuna SES (i.e., Fig. A1.1). This process allowed for the identification of any missing information about the SES.

For communication exchanges (2), interviewees were presented with a list of the organizations identified in the fishery and were asked about their frequency of communication with each of them, in terms of discussing fishery matters (Table A1.1). Communication frequency options were not often ( $1-4$ times/ year), sometimes (5-11 times/year), often (1-4 times/month, monthly), and a lot (more than once a week). This information allows for the measurement of social connectivity in the fishery, in the form of a communication network among organizations.
As part of the interview process, some stakeholders identified additional organizations in the fishery with whom they communicate, and these interactions were also recorded. Interactions with non-interviewed organizations ( 5 government or RFMO, and 5 NGOs and others) were also collected, but we were unable to assess interactions between non-interviewed organizations. In this way, we could map the organizations, or groups of organizations, identified in the SES.

For adaptive capacity preferences (3), interviewees were first asked to indicate what they believed were the most important adaptation actions for the long-term sustainability of the fishery (A1 Question 5 and SM Table 2 in Rubio, Hobday, and Ojea, unpublished manuscript). Afterward, they were presented with the list of 12 adaptive capacity strategies (see Table 1 and Table A1.2), and asked to value their importance using a 5-category Likert scale, including 1 (not important), 2 (slightly), 3 (moderately), 4 (very), and 5 (extremely important). Respondents repeated this process three times, ranking the importance of adaptive capacity strategies for their three most important adaptation actions. The specific question was, "How important would the following strategies be on a scale from 1 to 5 to achieve the most important adaptation actions to seek a sustainable fishery?" In this way, perceptions of the importance of adaptive capacity domains are linked to real adaptation actions in the fishery. This resulted in each respondent having three answers per adaptive capacity strategy, which were averaged to obtain a single value. Results were classified according to a 4-category scale: values between 1 and 2 were less important; values between 2 and 3 were slightly important; values between 3 and 4 were important; and values between 4 and 5 were very important. Finally, the importance of adaptive capacity strategies was also averaged by adaptive capacity domain.

\section{Data analysis}

In order to identify groups of actors agreeing on the importance of specific adaptive capacity strategies to the sustainability of the Basque tropical tuna fishery, we performed a hierarchical cluster analysis of the stakeholders' responses. This method of analysis is suitable for small sample sizes, i.e., typically less than 250 observations (Kaufman and Rousseeuw 2005). Clusters were determined through Ward's linkage method (Ward 1963) with Euclidean distances, implying a minimum increase in the total within-cluster variance (Murtagh and Legendre 2014). We then plotted a heatmap of the results and calculated a final importance score for each adaptive capacity group resulting from the hierarchical cluster analysis by averaging the original importance values of adaptive capacity strategies per domain of Cinner et al. (2018).

After clustering organizations with the same preferences for adaptive capacity strategies and domains, we analyzed the social network of communication between the organizations. The network is composed of nodes, which represent organizations or groups of organizations ( $n=23$, Fig. 1), and links, which indicate communication between organizations. We specifically elected to include only communication occurring more than once per month, in order to focus on the most active organizations in the fishery. We constructed the network as a set of directed communication ties between organizations, i.e., Actor A communicates frequently with Actor B, and/or Actor B communicates frequently with Actor A. We opted to include only 
incoming ties (in-degree), in order to account for the fact that not every organization agreed to be interviewed during the data collection process, and therefore not every organization contributed ties (out-degree). In this sense, all actors had the same chance of being nominated as receivers of communication. Afterward, we plotted the network, including both adaptive capacity groups and organization types in the visualization.

Next, we calculated descriptive statistics for the directed network using the "igraph" package (Csardi and Nepusz 2006). At the network level, density measures how many ties between actors exist relative to the maximum number of possible ties between actors. The average in-degree captures the mean number of times each actor was named by other actors when asked to identify who they frequently communicate with. The average path length is the mean number of ties separating any two actors, and represents the reachability of actors within the system. At the node level, indegree centrality is the number of incoming ties an actor possesses, and betweenness centrality represents the extent to which an actor indirectly facilitates connectivity with other actors in the network (Bodin and Crona 2009). Actors with high in-degree centrality scores can be thought of as conversational hubs because other actors communicate frequently with them. We also measured betweenness centrality for ties in the network, which captures the extent to which a tie makes other connections possible. In-degree centrality and betweenness centrality for both nodes and ties were normalized between 0 and 1 for ease of interpretation.

Last, we performed an ERGM analysis using the "statnet" package in R (Handcock et al. 2019; see goodness-of-fit diagnostics in Appendix 2). In an ERGM, the network is treated as the dependent variable, and network formation processes (e.g., centralization and homophily), operationalized as micro-level structural parameters, are the predictor variables (Levy and Lubell 2018). ERGMs use Monte Carlo Markov Chain maximum likelihood simulation to estimate the extent to which a set of defined structural parameters are over- or under-represented in the observed network (Cranmer and Desmarais 2011). The results of an ERGM are a set of coefficients for the specified network parameters included in the model, which represent the change in the log-odds of tie formation, and indicate the direction and magnitude of each parameter (Hileman and Lubell 2018).

ERGMs are constructed by selecting model terms that are informed by both theory and knowledge of the empirical setting (Alexander et al. 2015), and therefore we include the following terms that address the relationship between social connectivity and adaptive capacity preferences: geometrically weighted edgewise shared partners (gwesp) captures closure; geometrically weighted in-degree distribution (gwideg) captures centralization (note: the term actually measures anti-centralization, and therefore a negative coefficient denotes a tendency for actors to form ties with high-degree actors); and homophily (nodematch) captures whether actors of the same type and belonging to the same adaptive capacity group tend to form ties with other actors of the same type and group. We also include the following control parameters: baseline rates of tie formation (nodefactor) for each actor type and adaptive capacity group, and whether or not an actor was interviewed during the data collection process; network density (edges); and actors who are not connected to the network (isolates).

\section{RESULTS}

Actor preferences for adaptive capacity strategies and domains Hierarchical cluster analysis resulted in four distinct adaptive capacity groups (Fig. 2), each of which represents different sets of preferences for adaptive capacity strategies. We observe how the same actor types do not necessarily belong to the same adaptive capacity group, i.e., share the same views on adaptive capacity strategies. Group 1 and Group 2 are the smallest, and include only two actors each; Group 3 is the largest with six organizations, and all four organization types are represented; and Group 4 contains three actors, all belonging to the fishing industry. The importance given to each adaptive capacity strategy by each organization, which was used to identify the groups, is also displayed in Figure 2. Participation in international/national/ local forums (e) is the only adaptive capacity strategy considered to be important or very important by all organizations. Conversely, all organizations ranked credit/savings (b) and income diversity (g) as less or slightly important.

Fig. 2. Preferences for adaptive capacity strategies by actor type. The heatmap shows hierarchical clustering of the 13 organizations in the Basque tuna social-ecological systems that were interviewed (rows), according to the value they assigned to the different adaptive capacity strategies (columns). Importance values rank from 1 (dark orange, less important) to 5 (dark blue, very important). The four adaptive capacity groups resulting from the cluster analysis are represented by numbers on the left side of the dendogram. See Table 1 for the correspondence between letters (columns) and full names of adaptive capacity strategies.

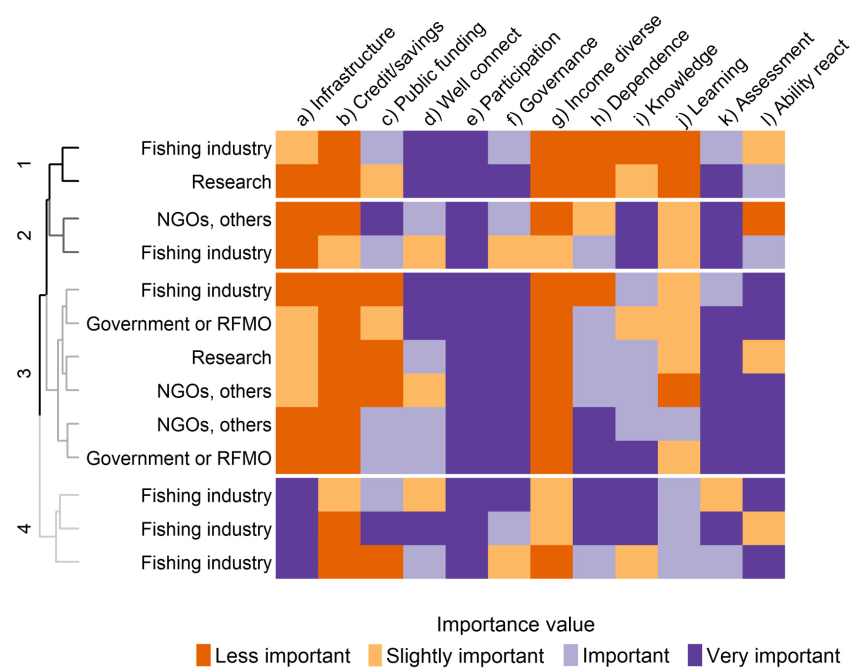

Figure 3 shows the average values for the resulting adaptive capacity groups per domain from Cinner et al. (2018). Group 1 is characterized by strong preferences for organization; Group 2 is characterized by its lack of strong preferences for or against any of the domains; Group 3 is characterized by strong preferences for organization and agency; and Group 4 is characterized by its preference for all adaptive capacity domains, as each domain was considered either important or very 
important. All groups thought organization is important or very important, but differed on the importance given to other domains. Groups 2, 3, and 4 all considered learning to be an important adaptive capacity domain, while Group 1 considered learning to be only slightly important. Group 4 considered both assets and flexibility to be important adaptive capacity domains, while the three remaining groups all considered these two domains to be of lesser importance (Group 1), slightly important (Group 2), or a mix of both (Group 3). Although clustered separately, these groups did not necessarily have opposing views. To recap, Group 1 gave importance to organization and agency; Group 2 to organization and learning; Group 3 to organization, agency, and learning; and Group 4 to all adaptive capacity domains. Except for Group 4, the rest had narrower views on adaptive capacity.

Fig. 3. Preferences for adaptive capacity domains per adaptive capacity group. Final importance scores are calculated for each adaptive capacity group (subplots) from the cluster analysis by averaging original importance values (y-axis) given to adaptive capacity strategies per domain ( $\mathrm{x}$-axis).

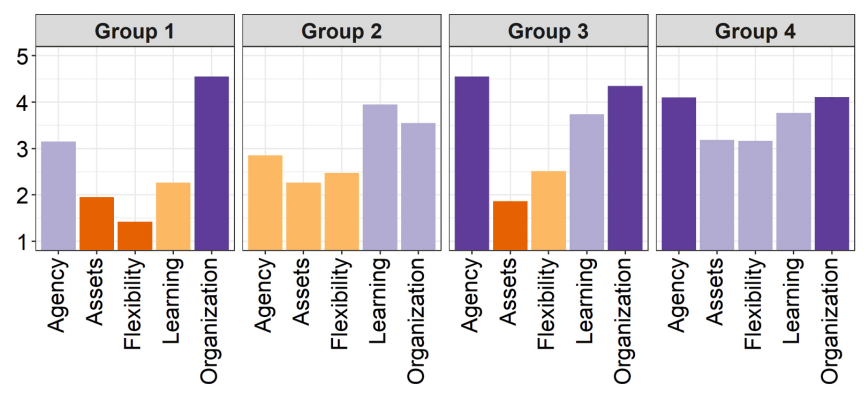

Importance value

Less important Slightly important Important Very important

\section{Social connectivity and adaptive capacity preferences}

Figure 4 presents the communication network among organizations in the Basque tuna SES. In-degree centrality and edge betweenness centrality are graphically represented by node size and tie color, respectively. Organizations in the center of the figure are those with more incoming ties, and include two actors from the fishing industry, two government entities, and one research organization. Ties with the highest edge betweenness link actors with important roles as connectors; the network may fracture if these actors were to stop communicating frequently. Network-level descriptive statistics indicate all organizations in the network are easily reachable (average path length $=1.99$ ), and on average possess multiple incoming ties from other organizations (average in-degree $=3.22$ ). Even given its small size, the network is still relatively dense $($ density $=0.15)$.

Figure 4 also shows nodes (actors) colored by adaptive capacity groups. The most central actors represented almost all adaptive capacity groups (Groups 1, 3, and 4). Actors belonging to adaptive capacity Group 1 tended to have the highest in-degree centrality and betweenness centrality in the network (Table 3 ). They were followed by Groups 3 and 4, which had similar in-degree values, but Group 3 had a higher betweenness centrality. Group 2 possessed the lowest betweenness centrality of all adaptive capacity groups in the network (Table 3). When looking at organization types as groups, the research group had the highest in-degree centrality and betweenness centrality values, followed by the fishing industry (Table 3 ). In spite of moderate in-degree centrality, government entities possessed the lowest betweenness centrality score after NGOs and others. NGOs and others also had the lowest in-degree.

Table 3. Mean degree centrality and betweenness centrality values by adaptive capacity group and organization type. Regional Fisheries Management Organization.

\begin{tabular}{ccc}
\hline \hline & $\begin{array}{c}\text { In-degree } \\
\text { centrality }( \pm \text { SD) }\end{array}$ & $\begin{array}{c}\text { Betweenness } \\
\text { centrality }( \pm \text { SD) }\end{array}$ \\
\hline Adaptive capacity group & & \\
Group 1 & $0.85( \pm 0.21)$ & $0.80( \pm 0.29)$ \\
Group 2 & $0.20( \pm 0.14)$ & $0.01( \pm 0.00)$ \\
Group 3 & $0.42( \pm 0.15)$ & $0.23( \pm 0.26)$ \\
Group 4 & $0.43( \pm 0.32)$ & $0.15( \pm 0.23)$ \\
Organization type & & \\
Fishing industry & $0.43( \pm 0.25)$ & $0.25( \pm 0.40)$ \\
Government or RFMO & $0.34( \pm 0.23)$ & $0.08( \pm 0.17)$ \\
NGOs, others & $0.12( \pm 0.13)$ & $0.09( \pm 0.23)$ \\
Research & $0.70( \pm 0.42)$ & $0.32( \pm 0.39)$ \\
\hline
\end{tabular}

Table 4 displays the results of the ERGM. In the model, we see a positive and significant coefficient for closure in the communication network, i.e., the more partners two actors share in common, the more likely they themselves are to share a tie. Centralization also had a positive and significant coefficient in the model, which means there was not a large variation in the number of ties each actor possessed in the network. The model indicated homophily was also a driver of tie formation in the network, specifically among actors of the same organization type, e.g., fishing industry actors tended to communicate more with other actors in the industry. However, homophily as a function of adaptive capacity group was not significant in the model.

Table 4. Exponential random graph model for the network of frequently connected organizations in the Basque tuna socialecological system. Coefficients for each term included in the model are shown with respective standard errors in brackets.

\begin{tabular}{lll}
\hline \hline & & Network \\
\hline Network & Closure (gwesp) & $0.906^{* *}(0.279)$ \\
processes & Centralization (gwideg) & $2.954^{*}(1.322)$ \\
Homophily & Adaptive capacity (nodematch) & $0.284(0.473)$ \\
& Actor type (nodematch) & $1.176^{* * *}(0.330)$ \\
Control & Baseline rates (nodefactor) & \\
parameters & Adaptive capacity (nodefactor) & \\
& AC Group 2 & $-1.400^{* *}(0.514)$ \\
& AC Group 3 & $-1.072 *(0.434)$ \\
& AC Group 4 & $-1.248^{* *}(0.453)$ \\
& Actor type (nodefactor) & \\
& Government & $0.716^{*}(0.350)$ \\
& NGOs/others & $0.140(0.296)$ \\
& Scientists & $0.202(0.343)$ \\
& Interviewed? (nodefactor) & $2.873 * * *(0.739)$ \\
& Density (edges) & $-7.329 * * *(1.091)$ \\
& Isolates (isolates) & $2.114(1.552)$ \\
\hline$* \mathrm{p}<0.1, * * \mathrm{p}<0.05, * * * \mathrm{p}<0.01$ &
\end{tabular}


Fig. 4. Network showing highly connected (communicating more than once a month) organizations in the Basque tuna social-ecological system $(n=23)$. Node shapes represent the actor type, node colors represent adaptive capacity groups, node sizes represent degree centrality, and tie boldness represents edge betweenness values. A label is only shown for government or Regional Fisheries Management Organizations (RFMO) above the corresponding node. Communication was not recorded between "NA" organizations as they were not interviewed.

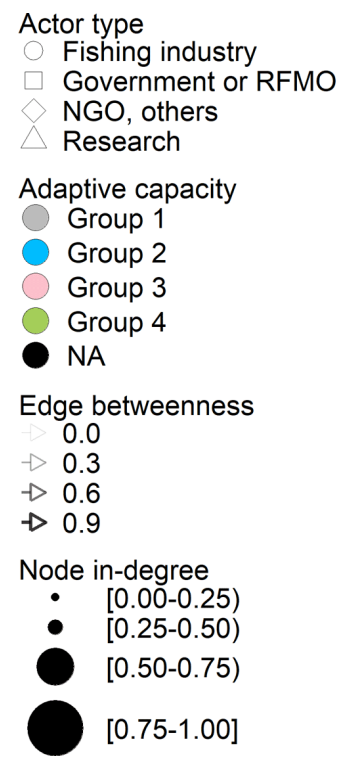

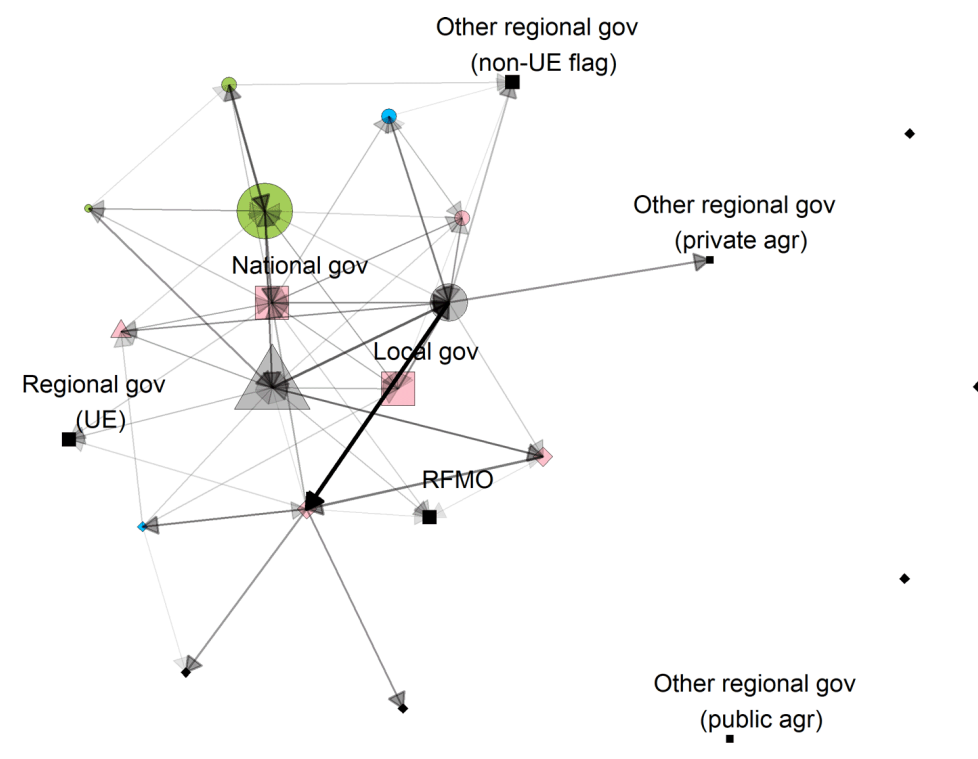

\section{DISCUSSION}

The importance that different stakeholders in the Basque tropical tuna fishery give to climate adaptive capacity domains is the core focus of this study, along with assessing why this is the case. Our results reflect the international nature of the governance regime where tuna fisheries are embedded (Allen 2010) because the organization domain from Cinner et al. (2018) is the only domain that all actors universally agree is important for sustaining the fishery in the face of global climate change. More specifically, all stakeholders agree that participation in international, national, and/or local forums is an important adaptive capacity strategy. In addition to participation in forums, being well connected with other actors and having good governance and leadership (in the social organization domain), and having resource status assessment and feedback mechanisms (in the learning domain) are highly valued by almost all actors. This is important in the setting of the ICCAT governance regime, where decision making about management measures is informed by stock assessments, and limits to the fishing activity of tropical tunas is derived from stock status (ICCAT 2016, 2019). These limits can be more or less restrictive as a result of political interests at the international level (Webster 2009). Other adaptive capacity strategies are generally seen as less important, e.g. having credit, savings, or income diversity. This is also likely related to the international nature of the fishery, where credit already exists, but inclusiveness of local stakeholders in the decision-making processes is almost nonexistent because rule making occurs among regional governments (Epstein et al. 2014, Pentz et al. 2018).

The results of the social network analysis shed light on the relationship between structures of communication among stakeholders in the fishery and their preferred adaptive capacity strategies. We found the fishery was characterized by strong communication among different actor types, which generally can help strengthen adaptive capacity (Whitney et al. 2017). Linking the network structure with the governance regime, Petersson et al. (2019) found that non-state actors, such as fishing industry representatives or NGOs, are interested in governance of fisheries and regularly attend RFMO meetings globally. These meetings are a good opportunity for strengthening networks, as representatives from many different organizations are able to interact with each other. Non-state actors, including scientific organizations and representatives of the fishing industry, were the most frequently communicated within the network. In addition, we found that central organizations tended to share similar preferences for adaptive capacity strategies (McPherson et al. 2001, Shepherd 2017), regardless of the type of actor, except for one fishing industry representative who had a holistic view of adaptive capacity (adaptive capacity Group 4).

Digging deeper into network structures and their relationship to adaptive capacity, highly central actors are well-positioned to share information widely through the network (Gibbs 2008, Bodin and Crona 2009, de Lange et al. 2019), and can catalyze widespread adoption of new behaviors through their social influence (Valente and Pumpuang 2007). Strategies to foster adaptive capacity in the fishery could be coordinated through the actors that occupy central positions and represent communication hubs. In our study, even though there is not a large variation in the degree of actors in the network, there is nevertheless a core group of more central actors. However, the majority of these central actors have narrower adaptive capacity 
preferences, focusing primarily on organization and agency, and to a lesser extent learning. This may potentially reduce adaptive capacity in the fishery if it similarly influences other actors' preferences (Bodin 2017). That said, we may not necessarily expect all different types of actors to consider all adaptive capacity domains as highly important, and it may even be natural for different types of actors to "specialize" in particular adaptive capacity domains, or particular suites to promote adaptive capacity. Inter-group collaboration, as indicated by the ERGM results, may signal there is a healthy mix of strategies to improve overall adaptive capacity in the fishery.

This raises the question of whether all domains of adaptive capacity need to be present for fisheries to be resilient to climate change. Or, in other words, whether there is substitutability among the elements of adaptive capacity. Yohe and Tol (2002) proposed the weakest link hypothesis, which entails that adaptive capacity may be restricted by the weakest of its underlying determinants. After performing a literature review, Cinner et al. (2018) suggest there is limited substitutability between domains of adaptive capacity with respect to shocks and long-term change. However, the authors also highlight that the weakest link idea has not yet been tested in fisheries. We do not directly address the substitutability hypothesis, but our results point in the direction of certain domains being perceived as more important than others, i.e., social organization. This suggests that some adaptive capacity options are considered secondary (or are seen as less important), which could result in a less resilient fishery. Another possibility is that these adaptive capacity options are considered secondary because they might already be covered within the fishery.

Moreover, similar actor types did not necessarily share the same views on the adaptive capacity strategies they considered most important for sustaining the fishery, which was the case among less than half of interviewed organizations. Two NGOs and others (from Group 3), two governments (from Group 3), and half of the fishing industry (Group 4) had the same views on adaptive capacity within their own actor type group (or sector). However, we found that actors do not tend to form ties with actors from the same adaptive capacity group, but they do tend to form ties with actors from the same sector. The tendency for closure within the network is primarily being driven by these within-sector ties. Research organizations and the fishing industry serve as bridging actors and provide more inter-group connectivity with NGOs and other actors, for example. It is useful to identify such bridging actors because they can help build support across groups when attempting to address environmental problems that require transformational changes in management and perceptions (Westley et al. 2013, Olsson et al. 2014).

Another concern arising from this research relates to the consequences of prioritizing adaptive capacity actions from a policy-making perspective. Policies that promote adaptive capacity are difficult to implement when stakeholders have varying preferences for adaptive capacity strategies. In the case of the Basque tropical tuna fishery, it would likely be easy to implement policies that target the organizational domain of adaptive capacity, given there was broad agreement among stakeholders concerning the importance of this particular domain. However, if the intention is to promote resilient fisheries, an effort should be made to foster a more holistic perspective of adaptive capacity. Given more holistic perspectives on adaptive capacity are represented by a few actors from the fishing sector, central actors could be involved in efforts to mobilize and encourage more integrated perspectives through strengthening their communication with these actors from the fisheries sector, thus improving the resilience of the governance system for the SES as a whole.

\section{CONCLUSIONS}

In this paper, we adopt a network-based approach to study the relationship between preferences for adaptive capacity strategies and social connectivity, in the form of communication, among stakeholders involved in an international large-scale fishery. We specifically investigate the Basque tropical tuna fishery in the east Atlantic Ocean, which is part of the ICCAT governance regime. Our results allow for the identification of adaptation strategies that are highly supported by all actors, which in this case constitutes strategies targeting the organizational domain of adaptive capacity. More specifically, promoting participation in international, national, and local forums would be well supported by all actors. When linking adaptive capacity preferences and social connectivity, the preferences of central actors are similar, because the majority focus on relatively few adaptive capacity domains, i.e., social organization, learning, and agency. This could be detrimental for promoting a fully resilient fishery, especially given actors from the fishing sector are the only ones who consider all adaptive capacity domains to be important. Thus, boosting connectivity with particular actors who have comprehensive views on adaptive capacity could help spread these views and promote a resilient fishery. Finally, the communication network does connect many different actor types in the fishery, which is an encouraging sign and could be used from a policymaking perspective to promote adaptive capacity through central actors acting as "communication hubs." Future research can help contextualize this study by examining regional governments independently, and further investigating adaptive capacity perceptions including views of the RFMO.

Responses to this article can be read online at: https://www.ecologyandsociety.org/issues/responses. php/12395

\section{Acknowledgments:}

This research was supported by the project CLOCK, under the European Horizon 2020 Program, ERC Starting Grant Agreement $n^{\circ} 679812$ funded by the European Research Council. It is also supported by the Basque Government through the BERC2018-2021 program and by the Spanish Ministry of Economy and Competitiveness MINECO through the BC3 Maria de Maeztu excellence accreditation MDM-2017-0714. We thank, without implicating, Ö. Bodin, I. Fetzer, and J.Rocha for scientific advice, and all the participants of the study who made it possible. 


\section{Data Availability:}

The code that supports the findings of this study is openly available in "tropituna_SNA_AdaptCapacity" at https://github.com/irrubiol tropituna_SNA_AdaptCapacity and https:/ldoi.org/10.5281/zenodo.4543248. The data that support the findings of this study are available on request from the corresponding author, I.R.

\section{LITERATURE CITED}

Adger, W. N. 2003. Social capital, collective action, and adaptation to climate change. Economic Geography 79 (4):387-404.

Alexander, S. M., D. Armitage, and A. Charles. 2015. Social networks and transitions to co-management in Jamaican marine reserves and small-scale fisheries. Global Environmental Change 35:213-225. https://doi.org/10.1016/j.gloenvcha.2015.09.001

Alexander, S. M., Ö. Bodin, and M. L. Barnes. 2018. Untangling the drivers of community cohesion in small-scale fisheries. International Journal of the Commons 12(1):519-547. https://doi. org/10.18352/ijc.843

Allen, R. 2010. International management of tuna fisheries. Arrangements, challenges and a way forward. FAO technical paper. Food and Agriculture Organization of the United Nations, Rome, Italy.

Barnes, M. L., P. Wang, J. E. Cinner, N. A. J. Graham, A. M. Guerrero, L. Jasny, J. Lau, S. R. Sutcliffe, and J. ZamborainMason. 2020. Social determinants of adaptive and transformative responses to climate change. Nature Climate Change 10 (9):823-828. https://doi.org/10.1038/s41558-020-0871-4

Berkes, F. 2011. Restoring unity. The concept of marine socialecological systems. Pages 9-28 in R. E. Ommer, R. I. Perry, K. Cochrane, and P. Cury, editor. World fisheries: a social-ecological analysis. Wiley-Blackwell, Oxford, UK. https://doi. org/10.1002/9781444392241.ch2

Bodin, Ö. 2017. Collaborative environmental governance: achieving collective action in social-ecological systems. Science 357(6352):eaan1114. https://doi.org/10.1126/science.aan1114

Bodin, Ö., S. M. Alexander, J. Baggio, M. L. Barnes, R. Berardo, G. S. Cumming, L. E. Dee, A. P. Fischer, M. Fischer, M. Mancilla Garcia, A. M. Guerrero, J. Hileman, K. Ingold, P. Matous, T. H. Morrison, D. Nohrstedt, J. Pittman, G. Robins, and J. S. Sayles. 2019. Improving network approaches to the study of complex social-ecological interdependencies. Nature Sustainability 2:551-559. https://doi.org/10.1038/s41893-019-0308-0

Bodin, Ö., and B. I. Crona. 2009. The role of social networks in natural resource governance: What relational patterns make a difference? Global Environmental Change 19(3):366-374. https:// doi.org/10.1016/i.gloenvcha.2009.05.002

Bodin, Ö., and M. Tengö. 2012. Disentangling intangible socialecological systems. Global Environmental Change 22(2):430-439. https://doi.org/10.1016/j.gloenvcha.2012.01.005

Bryman, A. 2016. Social research methods. Oxford University Press, Oxford, UK.
Cenek, M., and M. Franklin. 2017. An adaptable agent-based model for guiding multi-species Pacific salmon fisheries management within a SES framework. Ecological Modelling 360:132-149. https://doi.org/10.1016/j.ecolmodel.2017.06.024

Cinner, J. E., W. N. Adger, E. H. Allison, M. L. Barnes, K. Brown, P. J. Cohen, S. Gelcich, C. C. Hicks, T. P. Hughes, J. Lau, N. A. Marshall, and T. H. Morrison. 2018. Building adaptive capacity to climate change in tropical coastal communities. Nature Climate Change 8(2):117-123. https://doi.org/10.1038/s41558-017-0065-X

Cinner, J. E., T. R. McClanahan, M. A. MacNeil, N. A. J. Graham, T. M. Daw, A. Mukminin, D. A. Feary, A. L. Rabearisoa, A. Wamukota, N. Jiddawi, S. J. Campbell, A. H. Baird, F. A. Januchowski-Hartley, S. Hamed, R. Lahari, T. Morove, and J. Kuange. 2012. Comanagement of coral reef social-ecological systems. Proceedings of the National Academy of Sciences of the United States of America 109(14):5219-5222. https://doi. org/10.1073/pnas.1121215109

Cox, M., G. Arnold, and S. Villamayor Tomás. 2010. A review of design principles for community-based natural resource management. Ecology and Society 15(4):38. https://doi. org/10.5751/ES-03704-150438

Cranmer, S. J., and B. A. Desmarais. 2011. Inferential network analysis with exponential random graph models. Political Analysis 19(1):66-86. https://doi.org/10.1093/pan/mpq037

Csardi, G., and T. Nepusz. 2006. The igraph software package for complex network research. International Journal(Complex Systems):1695.

de Lange, E., E. J. Milner-Gulland, and A. Keane. 2019. Improving environmental interventions by understanding information flows. Trends in Ecology and Evolution 34 (11):1034-1047. https://doi.org/10.1016/j.tree.2019.06.007

Epstein, G., M. Nenadovic, and A. Boustany. 2014. Into the deep blue sea: commons theory and international governance of Atlantic Bluefin Tuna. International Journal of the Commons 8 (2):277-303. https://doi.org/10.18352/ijc.410

Erauskin-Extramiana, M., H. Arrizabalaga, A. J. Hobday, A. Cabré, L. Ibaibarriaga, I. Arregui, H. Murua, and G. Chust. 2019. Large-scale distribution of tuna species in a warming ocean. Global Change Biology 25(6):2043-2060. https://doi.org/10.1111/ gcb. 14630

Food and Agriculture Organization (FAO). 2018. The state of the world fisheries and aquaculture, meeting the sustainable development goals. FAO, Rome, Italy.

Freduah, G., P. Fidelman, and T. F. Smith. 2018. Mobilising adaptive capacity to multiple stressors: insights from small-scale coastal fisheries in the western region of Ghana. Geoforum 91:61-72. https://doi.org/10.1016/j.geoforum.2018.02.026

Free, C. M., J. T. Thorson, M. L. Pinsky, K. L. Oken, J. Wiedenmann, and O. P. Jensen. 2019. Impacts of historical warming on marine fisheries production. Science 363 (6430):979-983. https://doi.org/10.1126/science.aau1758

Fuller, E. C., J. F. Samhouri, J. S. Stoll, S. A. Levin, and J. R. Watson. 2017. Characterizing fisheries connectivity in marine 
social-ecological systems. ICES Journal of Marine Science 74 (8):2087-2096. https://doi.org/10.1093/icesjms/fsx128

García Molinos, J., B. S. Halpern, D. S. Schoeman, C. J. Brown, W. Kiessling, P. J. Moore, J. M. Pandolfi, E. S. Poloczanska, A. J. Richardson, and M. T. Burrows. 2016. Climate velocity and the future global redistribution of marine biodiversity. Nature Climate Change 6:83-88. https://doi.org/10.1038/nclimate2769

Gibbs, M. T. 2008. Network governance in fisheries. Marine Policy 32(1):113-119. https://doi.org/10.1016/j.marpol.2007.05.002

Halpern, B. S., M. Frazier, J. Afflerbach, J. S. Lowndes, F. Micheli, C. O'Hara, C. Scarborough, and K. A. Selkoe. 2019. Recent pace of change in human impact on the world's ocean. Scientific Reports 9:11609. https://doi.org/10.1038/s41598-019-47201-9

Handcock, M., D. Hunter, C. Butts, S. Goodreau, P. Krivitsky, and M. Morris. 2019. ergm: Fit, simulate and diagnose exponential-family models for networks. The Statnet Project. R package version 3.10.4, URL: https://CRAN.R-project.org/ package $=$ ergm https://doi.org/10.18637/jss.v024.i03

Hileman, J., and M. Lubell. 2018. The network structure of multilevel water resources governance in Central America. Ecology and Society 23(2):48. https://doi.org/10.5751/ES-10282-230248

Holsman, K. K., E. L. Hazen, A. Haynie, S. Gourguet, A. Hollowed, S. J. Bograd, J. F. Samhouri, and K. Aydin. 2019. Towards climate resiliency in fisheries management. ICES Journal of Marine Science 76(5):1368-1378. https://doi.org/10.1093/ icesjms/fsz031

International Commission for the Conservation of Atlantic Tunas (ICCAT). 2016. Recommendation by ICCAT on a multiannual conservation and management programme for tropical tunas. ICCAT, Madrid, Spain.

International Commission for the Conservation of Atlantic Tunas (ICCAT). 2019. Report of the Standing Committee on Research and Statistics (SCRS). ICCAT, Madrid, Spain.

Intergovernmental Panel on Climate Change (IPCC). 2018. Annex I: Glossary. J. B. R. Matthews, editor. In Global warming of $1.5^{\circ} \mathrm{C}$. An IPCC Special Report on the impacts of global warming of $1.5^{\circ} \mathrm{C}$ above pre-industrial levels and related global greenhouse gas emission pathways, in the context of strengthening the global response to the threat of climate change, sustainable development, and efforts to eradicate poverty. V. Masson-Delmotte, P. Zhai, H.-O. Pörtner, D. Roberts, J. Skea, P. R. Shukla, A. Pirani, W. Moufouma-Okia, C. Péan, R. Pidcock, S. Connors, J.B.R. Matthews, Y. Chen, X. Zhou, M.I. Gomis, E. Lonnoy, T. Maycock, M. Tignor, and T. Waterfield, editors. In press.

Intergovernmental Panel on Climate Change (IPCC). 2019. Summary for Policymakers. IPCC Special Report on the Ocean and Cryosphere in a Changing Climate. H.-O. Pörtner, D. C. Roberts, V. Masson-Delmotte, P. Zhai, M. Tignor, E. Poloczanska, K. Mintenbeck, A. Alegría, M. Nicolai, A. Okem, J. Petzold, B. Rama, N. Weyer, editors. In press.

Janssen, M. A., Ö. Bodin, J. M. Anderies, T. Elmqvist, H. Ernstson, R. R. J. McAllister, P. Olsson, and P. Ryan. 2006.
Toward a network perspective on the resilience of socialecological systems. Ecology and Society 11(1):15. https://doi. org/10.5751/ES-01462-110115

Kaufman, L., and P. Rousseeuw. 2005. Finding groups in data: an introduction to cluster analysis. Interscience, Wiley, New York, New York, USA.

Lam, V. W. Y., W. W. L. Cheung, G. Reygondeau, and U. R. Sumaila. 2016. Projected change in global fisheries revenues under climate change. Scientific Reports 6:32607. https://doi. org/10.1038/srep32607

Leslie, H. M., X. Basurto, M. Nenadovic, L. Sievanen, K. C. Cavanaugh, J. J. Cota-Nieto, B. E. Erisman, E. Finkbeiner, G. Hinojosa-Arango, M. Moreno-Báez, S. Nagavarapu, S. Reddy, A. Sánchez-Rodríguez, K. Siegel, J. J. Ulibarria-Valenzuela, A. Weaver, and O. Aburto-Oropeza. 2015. Operationalizing the social-ecological systems framework to assess sustainability. Proceedings of the National Academy of Sciences of the United States of America 112(19):5979-5984. https://doi.org/10.1073/ pnas. 1414640112

Levy, M. A., and M. N. Lubell. 2018. Innovation, cooperation, and the structure of three regional sustainable agriculture networks in California. Regional Environmental Change 18 (4):1235-1246. https://doi.org/10.1007/s10113-017-1258-6

Lindegren, M., and K. Brander. 2018. Adapting fisheries and their management to climate change: a review of concepts, tools, frameworks, and current progress toward implementation. Reviews in Fisheries Science and Aquaculture 26(3):400-415. https://doi.org/10.1080/23308249.2018.1445980

Lleonart, J., M. Demestre, P. Martín, J. Rodón, S. Sainz-Trápaga, P. Sánchez, I. Segarra, and S. Tudela. 2014. The co-management of the sand eel fishery of Catalonia (NW Mediterranean): the story of a process. Scientia Marina 78(S1):87-93. https://doi. org/10.3989/scimar.04027.25A

London, S., M. L. Rojas, M. M. Ibáñez Martin, F. Scordo, M. Andrea Huamantinco Cisneros, M. Luján Bustos, G. M. E. Perillo, and M. Cintia Piccolo. 2017. Characterization of an artisanal fishery in Argentina using the social-ecological systems framework. International Journal of the Commons 11(1):1-69. https://doi.org/10.18352/ijc.534

Lubell, M. 2013. Governing institutional complexity: the ecology of games framework. Policy Studies Journal 41(3):537-559. https://doi.org/10.1111/psj.12028

Mancilla García, M., and Ö. Bodin. 2019. Participation in multiple decision making water governance forums in Brazil enhances actors' perceived level of influence. Policy Studies Journal 47(1):27-51. https://doi.org/10.1111/psj.12297

Marshall, K. N., P. S. Levin, T. E. Essington, L. E. Koehn, L. G. Anderson, A. Bundy, C. Carothers, F. Coleman, L. R. Gerber, J. H. Grabowski, E. Houde, O. P. Jensen, C. Möllmann, K. Rose, J. N. Sanchirico, and A. D. M. Smith. 2018. Ecosystem-based fisheries management for social-ecological systems: renewing the focus in the United States with next generation fishery ecosystem plans. Conservation Letters 11(1):e12367. https://doi.org/10.1111/ conl.12367 
McGinnis, M. D., and E. Ostrom. 2014. Social-ecological system framework: initial changes and continuing challenges. Ecology and Society 19(2):30. https://doi.org/10.5751/ES-06387-190230

McPherson, M., L. Smith-Lovin, and J. M. Cook. 2001. Birds of a feather: homophily in social networks. Annual Review of Sociology 27:415-444. https://doi.org/10.1146/annurev.soc.27.1.415

Murtagh, F., and P. Legendre. 2014. Ward's hierarchical agglomerative clustering method: Which algorithms implement Ward's criterion? Journal of Classification 31:274-295. https:// doi.org/10.1007/s00357-014-9161-z

Ogier, E., S. Jennings, A. Fowler, S. Frusher, C. Gardner, P. Hamer, A. J. Hobday, A. Linanne, S. Mayfield, C. Mundy, A. Sullivan, G. Tuck, T. Ward, and G. Pecl. 2020. Responding to climate change: participatory evaluation of adaptation options for key marine fisheries in Australia's South East. Frontiers in Marine Science 7:97. https://doi.org/10.3389/fmars.2020.00097

Olsson, P., C. Folke, and T. P. Hughes. 2008. Navigating the transition to ecosystem-based management of the Great Barrier Reef, Australia. Proceedings of the National Academy of Sciences of the United States of America 105(28):9489-9494. https://doi. org/10.1073/pnas.0706905105

Olsson, P., V. Galaz, and W. J. Boonstra. 2014. Sustainability transformations: a resilience perspective. Ecology and Society 19 (4):1. https://doi.org/10.5751/ES-06799-190401

Ostrom, E. 1990. Governing the commons: the evolution of institutions for collective action. Cambridge University Press, New York, New York, USA.

Ostrom, E. 2009. A general framework for analyzing sustainability of social-ecological systems. Science 325:419-422. https://doi.org/10.1126/science.1172133

Partelow, S. 2018. A review of the social-ecological systems framework: applications, methods, modifications, and challenges. Ecology and Society 23(4):36. https://doi.org/10.5751/ES-10594-230436

Partelow, S., and C. Boda. 2015. A modified diagnostic socialecological system framework for lobster fisheries: case implementation and sustainability assessment in Southern California. Ocean \& Coastal Management 114:204-217. https:// doi.org/10.1016/j.ocecoaman.2015.06.022

Pelling, M., C. High, J. Dearing, and D. Smith. 2008. Shadow spaces for social learning: a relational understanding of adaptive capacity to climate change within organisations. Environment and Planning A 40(4):867-884. https://doi.org/10.1068/a39148

Pentz, B., N. Klenk, S. Ogle, and J. A. D. Fisher. 2018. Can regional fisheries management organizations (RFMOs) manage resources effectively during climate change? Marine Policy 92:13-20. https://doi.org/10.1016/i.marpol.2018.01.011

Perry, R. I., R. E. Ommer, M. Barange, S. Jentoft, B. Neis, and U. R. Sumaila. 2011. Marine social-ecological responses to environmental change and the impacts of globalization. Fish and Fisheries 12(4):427-450. https://doi.org/10.1111/j.1467-2979.2010.00402. $\underline{x}$

Petersson, M. T., L. M. Dellmuth, A. Merrie, and H. Österblom. 2019. Patterns and trends in non-state actor participation in regional fisheries management organizations. Marine Policy 104:146-156. https://doi.org/10.1016/j.marpol.2019.02.025

Pinsky, M. L., G. Reygondeau, R. Caddell, J. Palacios-Abrantes, J. Spijkers, and W. W. L. Cheung. 2018. Preparing ocean governance for species on the move. Science 360(6394):1189-1191. https://doi.org/10.1126/science.aat2360

Pita, P., D. Fernández-Vidal, J. García-Galdo, and R. Muíño. 2016. The use of the traditional ecological knowledge of fishermen, cost-effective tools and participatory models in artisanal fisheries: towards the co-management of common octopus in Galicia (NW Spain). Fisheries Research 178:4-12. https://doi.org/10.1016/j.fishres.2015.07.021

Poloczanska, E. S., M. T. Burrows, C. J. Brown, J. García Molinos, B. S. Halpern, O. Hoegh-Guldberg, C. V Kappel, P. J. Moore, A. J. Richardson, D. S. Schoeman, and W. J. Sydeman. 2016. Responses of marine organisms to climate change across oceans. Frontiers in Marine Science 3:62. https://doi.org/10.3389/ fmars.2016.00062

Preiser, R., R. Biggs, A. De Vos, and C. Folke. 2018. Socialecological systems as complex adaptive systems: organizing principles for advancing research methods and approaches. Ecology and Society 23(4):46. https://doi.org/10.5751/ES-10558-230446

R Core Team. 2018. R: A language and environment for statistical computing. R Foundation for Statistical Computing, Vienna, Austria.

Rivera, A., S. Gelcich, L. García-Florez, J. L. Alcázar, and J. L. Acuña. 2014. Co-management in Europe: insights from the gooseneck barnacle fishery in Asturias, Spain. Marine Policy 50:300-308. https://doi.org/10.1016/i.marpol.2014.07.011

Rubio, I., U. Ganzedo, A. J. Hobday, and E. Ojea. 2020. Southward re-distribution of tropical tuna fisheries activity can be explained by technological and management change. Fish and Fisheries 21(3):511-521. https://doi.org/10.1111/faf.12443

Scott, J., and P. J. Carrington. 2014. The SAGE handbook of social network analysis. SAGE, London, UK. https://doi. org/10.4135/9781446294413

Shepherd, H. R. 2017. The structure of perception: how networks shape ideas of norms. Sociological Forum 32(1):72-93. https:// doi.org/10.1111/socf.12317

Smit, B., and J. Wandel. 2006. Adaptation, adaptive capacity and vulnerability. Global Environmental Change 16(3):282-292. https://doi.org/10.1016/j.gloenvcha.2006.03.008

Spijkers, J., and W. J. Boonstra. 2017. Environmental change and social conflict: the northeast Atlantic mackerel dispute. Regional Environmental Change 17(6):1835-1851. https://doi.org/10.1007/ s10113-017-1150-4

Ugalde, R. 2014. Atuneros congeladores vascos: Un sector de relevancia económica mundial. BETA III M, Bilbao, Spain.

Ugalde, R., and S. Samano. 2019. El subsector atunero congelador en cifras, 2011-2017. Ministerio de Agricultura, Pesca y Alimentación. Spanish Ministry of Agriculture, Fisheries and Food, Madrid, Spain. 
Valente, T. W., and P. Pumpuang. 2007. Identifying opinion leaders to promote behavior change. Health Education and Behavior 34(6):881-896. https://doi.org/10.1177/1090198106297855

Ward Jr., J. H. 1963. Hierarchical grouping to optimize an objective function. Journal of the American Statistical Association 58(301):236-244. https://doi.org/10.1080/01621459.1963.10500845

Webster, D. G. 2009. Adaptive governance: the dynamics of Atlantic fisheries management. MIT Press, Cambridge, Massachusetts, USA. https://doi.org/10.7551/mitpress/9780262$\underline{232708.001 .0001}$

Westley, F. R., O. Tjornbo, L. Schultz, P. Olsson, C. Folke, B. Crona, and Ö. Bodin. 2013. A theory of transformative agency in linked social-ecological systems. Ecology and Society 18(3):27. https://doi.org/10.5751/ES-05072-180327

Whitney, C. K., N. J. Bennett, N. C. Ban, E. H. Allison, D. Armitage, J. L. Blythe, J. M. Burt, W. Cheung, E. M. Finkbeiner, M. Kaplan-Hallam, I. Perry, N. J. Turner, and L. Yumagulova. 2017. Adaptive capacity: from assessment to action in coastal social-ecological systems. Ecology and Society 22(2):22. https:// doi.org/10.5751/ES-09325-220222

Yletyinen, J., J. Hentati-Sundberg, T. Blenckner, and Ö. Bodin. 2018. Fishing strategy diversification and fishers' ecological dependency. Ecology and Society 23(3):28. https://doi. org/10.5751/es-10211-230328

Yohe, G., and R. S. J. Tol. 2002. Indicators for social and economic coping capacity - moving toward a working definition of adaptive capacity. Global Environmental Change 12(1):25-40. https://doi. org/10.1016/S0959-3780(01)00026-7 


\section{Appendix 1. INTERVIEW QUESTIONS}

The questions used during stakeholders' interviews to elaborate the article titled "Social connectivity and preferences for adaptive capacity in large-scale fisheries" are included below. The original interview was done in Spanish but has been translated to English (see Question 1 to 6).

Question 1. Background questions:

- What is your organization name?

- Where is it located (headquarters)?

- What is your gender? $\square$ female $\square$ male $\square$ other

- What is your current position?

- How many years have you been working in the tropical tuna sector?

○ How old are you? $\square$ 18-24 $\square$ 25-34 $\square$ 35-44 $\square$ 45-54 $\square$ 55-64 65 or more

- What is the main role of your organization in the tropical tuna sector?

- How much does your organization influence decision-making about the management of tropical tunas? $\square$ Very Little $\square$ Moderately $\square$ A lot

Question 2. The following picture summarizes the components of the tropical tuna extractive activity by Basque ship-owners (EU flags and others) in the Atlantic Ocean. We want to identify all the relevant elements, from species to actors and institutions. Can you look at the figure (Figure A1.1) and answer the "grey" questions please?

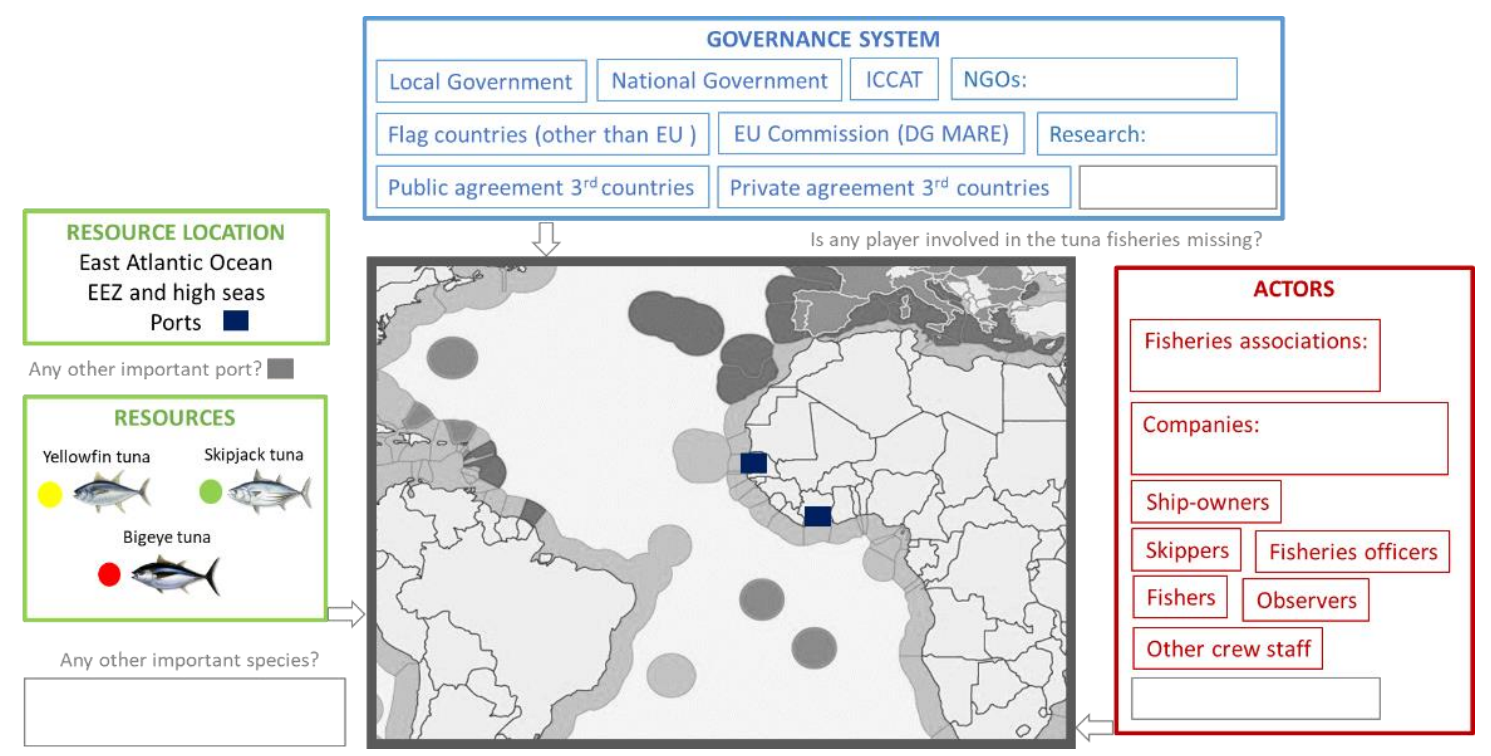

Figure A1.1 Conceptual model of the Basque tuna SES. This figure was shown to stakeholders in order to complete our case study understanding and identifying other important stakeholders. 
Question 3. What actors from the blue and red boxes is your organization related to? Tick it on the figure.

Question 4. Based on the actors with whom your organization is related, that you have pointed out. Can you tell me how much your organization communicates with the other org. and why? Communication is understood as emails, phone calls, face-to-face conversations, meetings, letters and other forms of dialog between 2 organizations.

Table A1.1 Questions asked to build the communication network of the Basque tuna SES.

\begin{tabular}{|c|c|c|c|}
\hline $\begin{array}{l}\text { Organization2 } \\
\text { (org2) }\end{array}$ & $\begin{array}{l}\text { How many times is your org } \\
\text { usually contacting org } 2 \text { ? } \\
\text { Choose one option }\end{array}$ & \multicolumn{2}{|c|}{$\begin{array}{l}\text { What is the usual objective when contacting } \\
\text { org2? } \\
\text { Mark as many as needed }\end{array}$} \\
\hline Local government & $\begin{array}{l}\square \text { Not often (1-4 } \\
\text { times/year) } \\
\square \text { Sometimes (5-11 t/year) } \\
\square \text { Often (1-4 t/m, monthly) } \\
\square \text { A lot (More than once a } \\
\text { week) }\end{array}$ & \multicolumn{2}{|c|}{$\begin{array}{l}\square \text { Making management decisions } \\
\text { (Regulations, TACs, FADs, closures...) } \\
\square \text { Scientific advice } \\
\square \text { Reporting activity } \\
\square \text { Legal procedures (Sanctioning...) } \\
\square \text { Administrative tasks (Construction of a vessel, } \\
\text { licenses, catch payment...) } \\
\square \text { Collaboration } \\
\square \text { Private services } \\
\square \text { Others: }\end{array}$} \\
\hline $\begin{array}{l}\text { National } \\
\text { government }\end{array}$ & $\begin{array}{l}\text { Not often (1-4 } \\
\text { times/year) } \\
\square \text { Sometimes (5-11 t/year) } \\
\square \text { Often (1-4 t/m, monthly) } \\
\square \text { A lot (> once a week) }\end{array}$ & $\begin{array}{l}\square \text { Making management } \\
\text { decisions } \\
\square \text { Scientific advice } \\
\square \text { Reporting activity } \\
\square \text { Legal procedures }\end{array}$ & $\begin{array}{l}\text { Administrative } \\
\text { tasks } \\
\square \text { Collaboration } \\
\square \text { Private services } \\
\square \text { Others: }\end{array}$ \\
\hline ICCAT & $\begin{array}{l}\text { Not often (1-4 } \\
\text { times/year) } \\
\square \text { Sometimes (5-11 t/year) } \\
\square \text { Often (1-4 t/m, monthly) } \\
\square \text { A lot (> once a week) }\end{array}$ & $\begin{array}{l}\square \text { Making management } \\
\text { decisions } \\
\square \text { Scientific advice } \\
\square \text { Reporting activity } \\
\square \text { Legal procedures }\end{array}$ & $\begin{array}{l}\text { Administrative } \\
\text { tasks } \\
\square \text { Collaboration } \\
\square \text { Private services } \\
\square \text { Others: }\end{array}$ \\
\hline EU Commission & $\begin{array}{l}\square \text { Not often (1-4 } \\
\text { times/year) } \\
\square \text { Sometimes (5-11 t/year) } \\
\square \text { Often (1-4 t/m, monthly) } \\
\square \text { A lot (> once a week) }\end{array}$ & $\begin{array}{l}\square \text { Making management } \\
\text { decisions } \\
\square \text { Scientific advice } \\
\square \text { Reporting activity } \\
\square \text { Legal procedures }\end{array}$ & $\begin{array}{l}\square \text { Administrative } \\
\text { tasks } \\
\square \text { Collaboration } \\
\square \text { Private services } \\
\square \text { Others: }\end{array}$ \\
\hline Etc. & Etc. & Etc. & \\
\hline
\end{tabular}

Question 5. From the actions LIST, which ones do you think are the 3 most important actions to maintain the fleet activity in the future (i.e. for a sustainable fishery)? (1: most important; 3: less important).

1.

2. 3.

The list of adaptation actions will be published in the SM Table 2 of Rubio et al. in prep. and the answer to the question is in the same article. 
Question 6. How important would the following options (Table A1.2) be on a scale from 1 (not important) to 5 (very important) to achieve the actions chosen in the previous question? Answer by action (A1, A2 and A3).

Table A1.2 List of adaptive capacity strategies.

\begin{tabular}{|c|c|c|c|}
\hline & A1 & $\mathrm{A} 2$ & $\mathrm{~A} 3$ \\
\hline \multicolumn{4}{|l|}{ Specific infrastructure (ports, vessels...) } \\
\hline \multicolumn{4}{|l|}{ Credit or savings } \\
\hline \multicolumn{4}{|l|}{ Public funding } \\
\hline \multicolumn{4}{|l|}{ To be well connected with other players } \\
\hline \multicolumn{4}{|l|}{ To participate in international/national/local forums } \\
\hline \multicolumn{4}{|l|}{ Good quality of governance and leadership } \\
\hline \multicolumn{4}{|l|}{ Income diversity } \\
\hline \multicolumn{4}{|l|}{ Level of dependence on natural resources } \\
\hline \multicolumn{4}{|l|}{$\begin{array}{l}\text { Knowing that the environment is continuously changing including the species } \\
\text { and ecosystems }\end{array}$} \\
\hline \multicolumn{4}{|l|}{ Intergenerational learning capacity } \\
\hline \multicolumn{4}{|l|}{ Resource status assessment and feedback mechanisms } \\
\hline Ability to react to the changes (e.g. distribution, abundance, climatic risks) & & & \\
\hline
\end{tabular}


Appendix 2. ERGM GOODNESS-OF-FIT DIAGNOSTICS

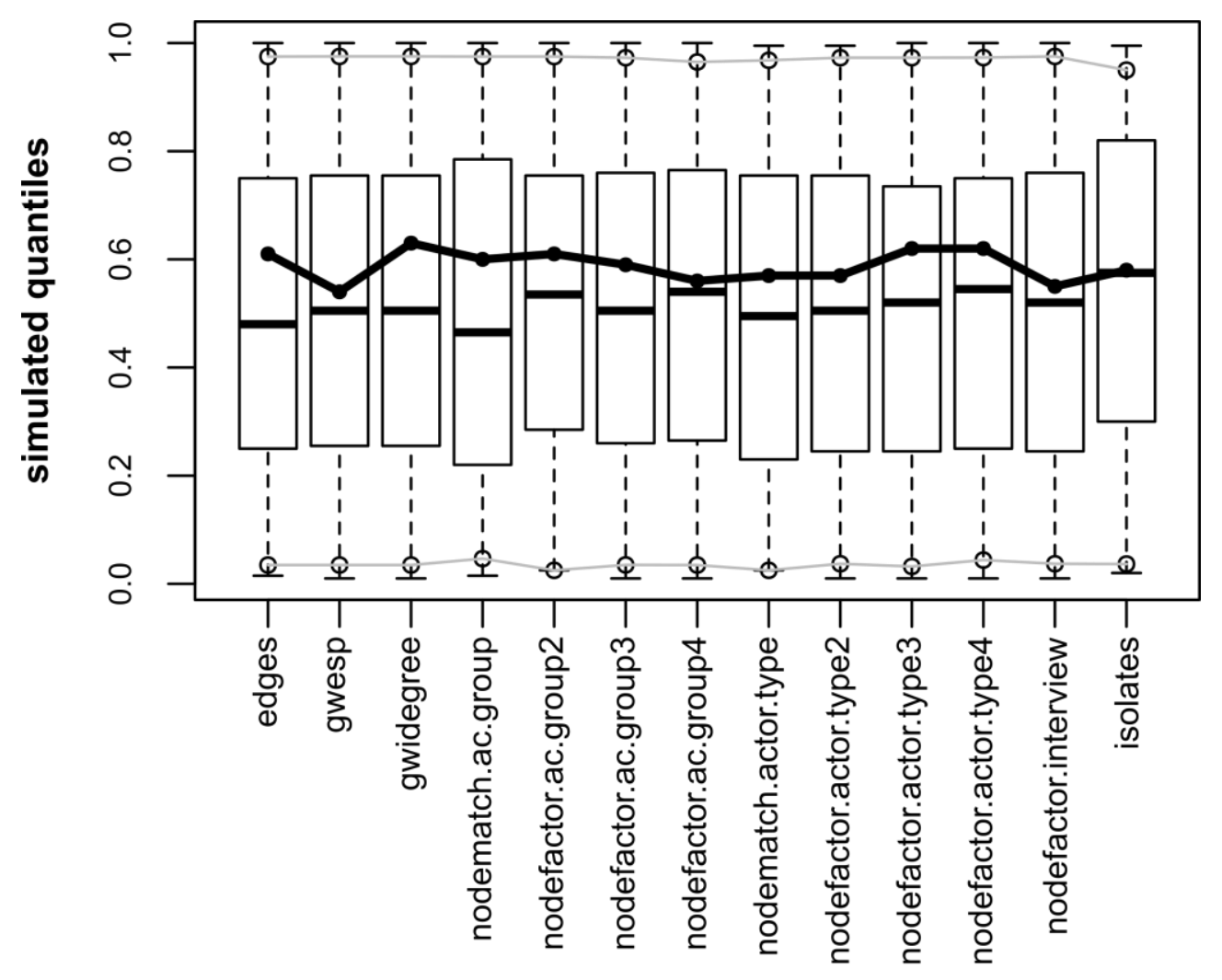

model statistics

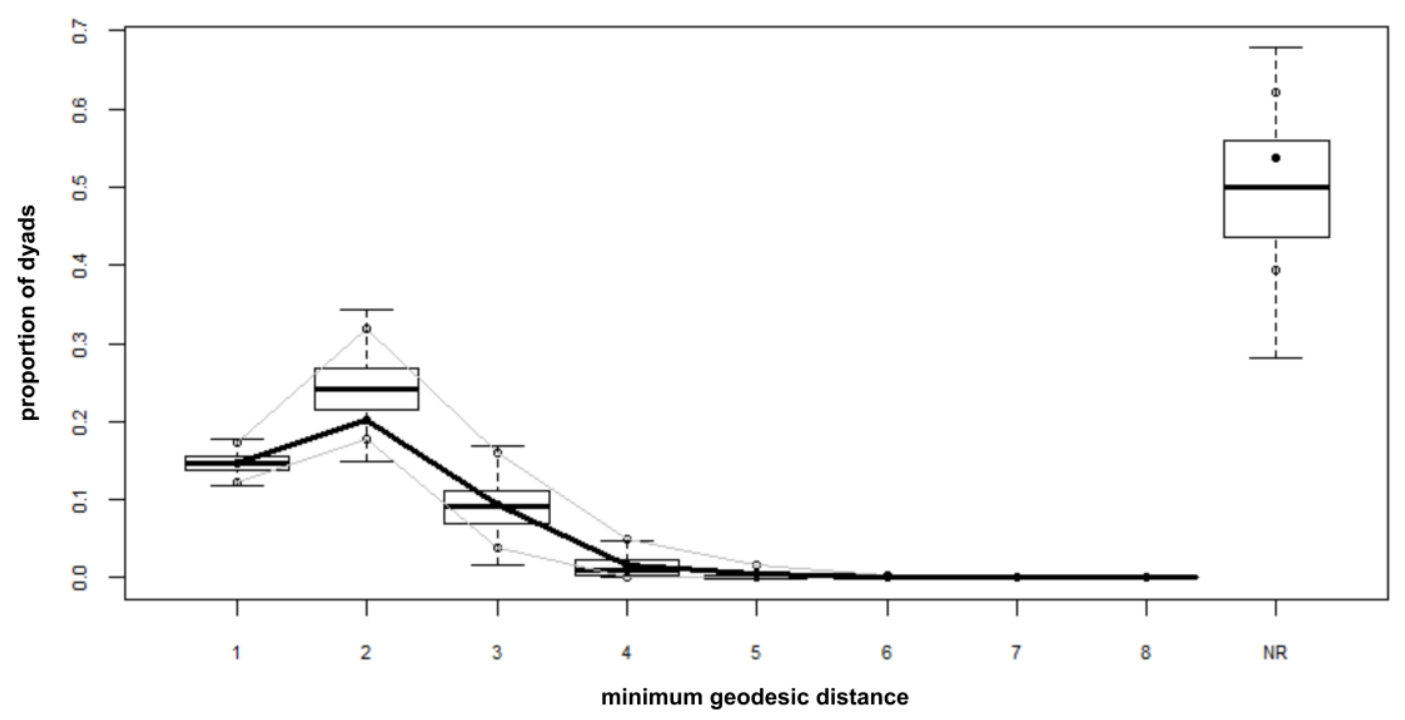



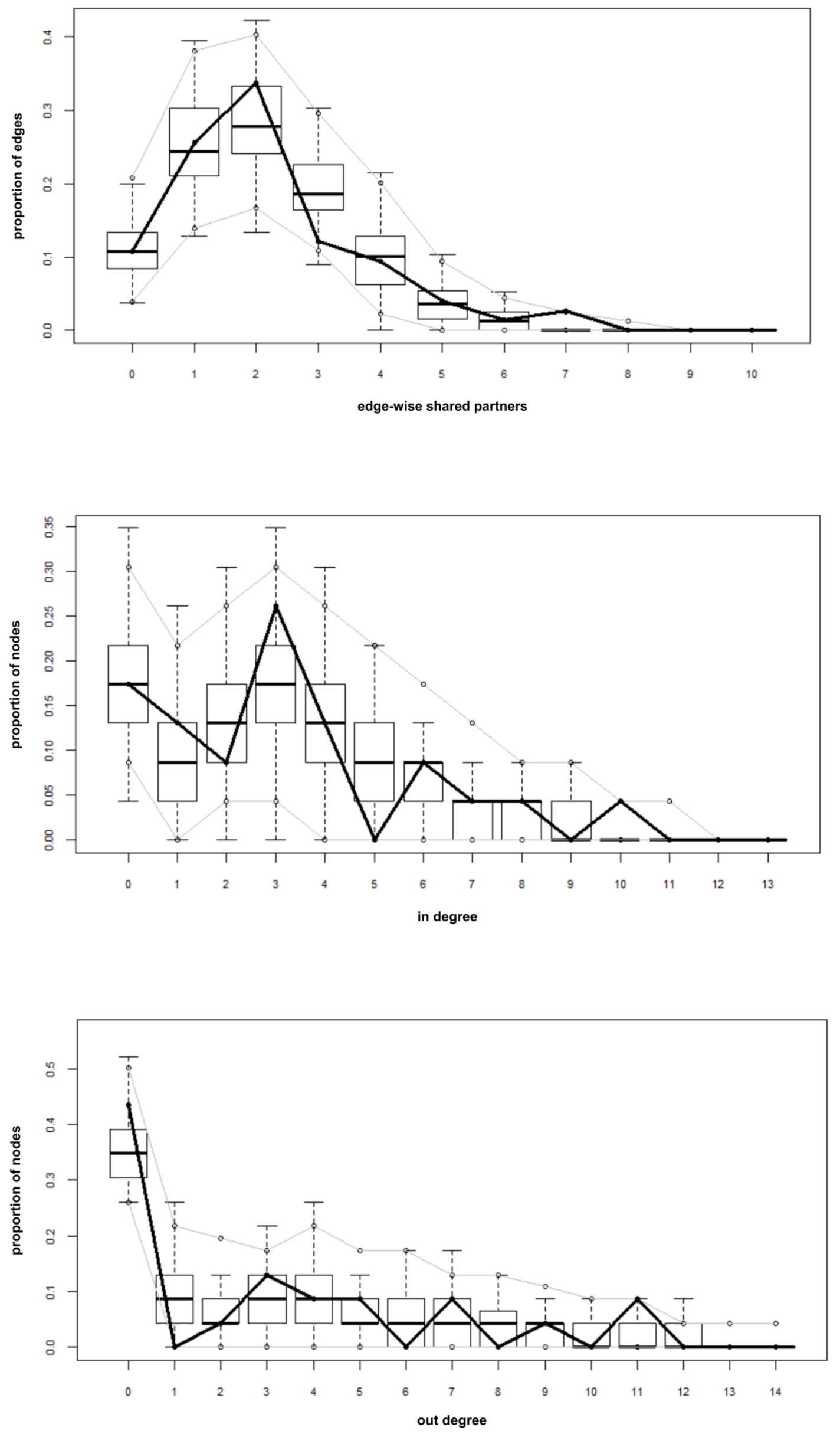